\title{
Translation and the Metaphor of Relation: Confluences of Answerability
}

\author{
Mahmoud M. Gewaily \\ Minia University, Egypt
}

Received: 18-11- 2013

doi:10.7575/aiac.ijclts.v.2n.1p.22
Accepted: 23-12- 2013

Published: 10-01- 2014

\begin{abstract}
This article aims to explore the blurred lines of thoughts on the spirit of translation as a synthetic sign of interaction between the abundant science of cognition and the philosophy of the unfinalized dialogism of the Russian cultural theorist and social philosopher Mikhail Bakhtin (1895-1975). First, it shows the ineluctable view of cultural differences as a house to translation. Second, because humans are different, the article proceeds to reflect the interplay of some views on culture, language and thought, seeking to envisage the confluent relation of the dialogic trans-formation of the act/tact in translation at play. Third, the metaphor of relation is illustrated through the one postcolonial example in the particular setting of the Israel-Palestine political conflict in language. Together with such lines of confluence came a belief about the holistic architectonics of translation in the development of an attitude towards the 'dialogic turn' of 'answerability' in translation in the future.
\end{abstract}

Keywords: Translation, culture, language, thought, dialogism

\section{Cultural Differences}

Cultural differences are the most inalienable of all humans. An analysis of the mental equipment of the translator raises questions not just of linguistic competence but also something beyond the grasp of any single translator, the problem of cultural differences. Are we really, as philosopher Ludwig Wittgenstein (1953) and psychologist Lev Vygotsky (1978) saw so clearly, fish in the water of culture? What is meant by the ways in which people use language or how do people use language differently?

Since starting to jot down some notes on the writing of this article, I have been always ambivalent about the title. As Paul Ricoeur, cited by Anthony Giddens (1990), has written: "When we discover that there are several cultures instead of just one and consequently at the time when we acknowledge the end of a sort of cultural monopoly, be it illusory or real, we are threatened with the destruction of our own discovery. Suddenly it becomes possible that there are just others, that we ourselves are an 'other' among others". For Ricoeur, the precise sense of survival is to consciously believe in differences among cultures in order to escape a dead end. The mere belief that there is a 'cultural monopoly' means that there are no cultural differences. Most importantly, this cultural difference is located even among adherents to the same culture as it is based on both what sorts of material are significant and how such material is adopted to be markers of their individuality. ${ }^{1}$ Therefore, the exponents' world-views within disciplines explain how much cognition helps, to a large degree, to integrate variations between cultures.

Certainly, language is to set human beings off as unique within the animal kingdom because of the creative manipulation of cognitive resources. For the most part, however, the culture of the current age is terribly concerned with science. Every science has its own identity or language of discourse in order to be identified from another, not only in the content or knowledge, but in the approach to truth as well. This identity of the language of science is ineluctable, as the nature of the one object per se is too vague to be assimilated through any one science. That is, nature could perhaps be prescient philosophically, suggesting that a new way of representing with understanding or resisting some findings through the exploratory lens of science.

Being object to changes over times, translation as activity has been bifurcated or hybridized since it has always been at the crossroads of an increasing number of various distinct academic disciplines or traditions., for example, communication theory, information theory, sociology, psychology, philology, sociolinguistics, linguistics, cognitive linguistics, semiotics, hermeneutics, rhetoric and aesthetics. This all suggests that translation lies in a vast web of interconnections which raises up the problem of "translatability" in view of discourse and the exercise of dialogue (human communication) to how the approach of language and culture is central to any interdisciplinary piece of research. These traditions have had enormous impact on many different aspects and practices of translation, making of translation a comprehensive, honorably synthetic theory such as postcolonial translation theory, cognitive approaches to translation, etc. This paper, thus, attempts to examine or develop a holistic view of translation as transfusion as it aims to explore the relevance of translation theory to the fields of communication theory, postcolonial theory, philosophy of language, cognitive linguistics, and cultural semiotics.

${ }^{1}$ If you display your heel while talking to someone from the Middle East that is a sign of insult in Arabic culture, but in the US where people behave freely a similar act normally does not hurt feelings. 


\section{The Confluence of Cognition \& Dialogism}

This paper emphasises the analytical tools of a dialogic act in translation required to describe translation in the light of its dialogic turn of answerability. This paper is essentially based on the imaginative channels of communication between the self and the other in view of the two propositions 'from' and 'through.' By means of referring briefly to the relationships from translation through the question of cognition and the philosophy of language, the key point is to synthesize the dialogic sign task in translation. Comparing the two questions of cognition and dialogism is to comparatively elucidate how language and culture can reflect the nature of social binary oppositions. Such a comparison allows the deconstruction of binaries such as male/female, superior/ inferior, master/slave relationships that create cultural norms. These binaries include literary concepts and terminology such as "answerability," "architectonics," "polyphony," "heteroglossia," the "chronotope," "novelization," and the "carnivalesque." From these many concepts I propose to focus on dialogism to explore, extend, and apply to a variety of ideological literary voices from different cultural diasporas. The result will be an understanding of another aspect of Bakhtin's, concept of polyphony .

Then, this view of confluences will include the basic elements of cognition, and dialogism, and how both establish the metaphor of relation.

\subsection{The Question of Cognition}

Individuals can learn through various strands of cognitive investigation that have come together from linguistics, psychology, philosophy, and other disciplines that lead to the emergence of the interdisciplinary field of cognitive science. A linguist differs from his colleagues studying other sister disciplines in exploring language from the inside with its own internal rules, perhaps in the organization of the human mind. In view of Michael Tomasello (1999: 150), language cannot be separated from cognition because language is "a form of cognition". This is so because language embodies the daily acts of language users in a community in their shared beliefs and practices. Explanations of this type of thinking propose the biological nature of language incorporated into a communication system that deals with, says Eric Lenneberg (1967), the differences between species, whereas the theory of learning in psychology is concerned with what is common to the human nature of descendants that are known today as homo sapiens. Because Lenneberg's study is based on differences, he justifies any paradoxical encounters during his investigation by reference to the widely acknowledged view that the essential principles underlying human language(s) consist of "arbitrary, cultural conventions" (2). Linguists used to study 'the abstract nature of linguistic structure' (3) away from its actual performance as the function of sociolinguistics, or away from the 'situations' of the language users called pragmatics, which is the study of language- in- use, or the study of contextual elements in verbal communication. Below you will find the three key points to focus on to connect them as part of cognitive research.

a. There is enough to learn through various strands of cognitive investigation that have come together from linguistics, psychology, philosophy, and other disciplines that lead to the emergence of the interdisciplinary recently -created field of cognitive science. The second matter to be considered after the view of schemata is the question of cognition. In phonetics, what is essentially significant is the fact that a meaningless phoneme leads to a meaningful morpheme (or word). If it is necessary to look for a meaning of a word, for example 'cognition', it suffices to say that the measurement of meaning, in the view of Charles Osgood (1957), includes at least as many meanings of "meaning" as there are "disciplines." Still, there are even more meanings than these many disciplines because "exponents within disciplines," as Osgood put it, "do not always agree with one another"(2). The process of cognition is a major inquiry into what is common and what is different in view of some mental ways of individual thought; this process is related to all so-called cognitive. In The Longman Dictionary of Contemporary English (1995) the meaning of 'cognitive' refers to "the process of knowing, understanding, and learning something" such as cognitive psychology, cognitive anthropology, etc (254). All humans engage in a lifetime's pursuit of information and share the same physical world. However, they are essentially different. The difference in their mental processing means that cognition is obviously interested in 'what' is the mental code of people and in 'how' do these people construe their perceptions of the world and reflect their worldview(s). "Not only do cultures differ among one another in their organization of material phenomena," asserts Stephen A. Tyler (1969: 3) in the attempt to explain the essential goal of cognitive anthropology, embraced under the rubric 'language and culture,' "they differ as well in the kinds of material phenomena they organize".

b. The hallmark of interest is assigned nowadays to science and not to philosophy as it used to be. How knowledge is connected to science is the purpose of Henry Plotkin's Darwin Machines and The Nature of Knowledge (1993). There are two aspects of knowledge: something outside and something inside the head in its relation to feeling. One can also know about things that have no place in real life through the use of imagination. Actually, the "relational characteristics of knowledge" reminds me of the concept of the self-consciousness in its relational aspects (4). The acts of knowing by both senses and mind are relevant to the knowledge of culture. This happens when knowledge is shared with others because this leads to what cultural theorists emphasize as the existence of "cultural knowledge- or simply culture" (10). Most importantly, this cultural difference is located even among adherents to the same culture as it is based on both what sorts of material are significant and how such material is adopted to be markers of their individuality. What is the nature of human cognition? Do human beings perceive reality differently?

Philosophers such as Dan Sperber and Deirdre Wilson (1986: 41) present a perspective on a particular issue to be worked out, and stress that: "Since physical environments are never strictly identical, and since cognitive abilities are affected from one person to another, people never share their total cognitive environments. Moreover, to say that two people share a cognitive environment does not imply that they make the same assumptions: merely that they are 
capable of doing so."The two major principles of relevance and context are discussed in Sperber and Wilson's book present a relationship between the human communicative ability and human cognitive competence. The mere saying that two people share a cognitive environment does not necessarily mean that they should propose the same assumptions but that they are merely capable of doing so.

The fact that linguistics is the study of language, there is strong evidence of an overlap between linguistics and linguistic philosophy (theory of language) in a great number of studies. However, just a small number of studies (Gorlée 1994; Chesterman 1997, for example) are thinking about the significance of relaying the Dialogic Principle (DP) to translation, but none has been pleading for a comparative approach of dialogic translation stylistics made into a full analysis to begin to crack open wide. For example, Chesterman $(1997$, pp.164, 194) glosses DP in translation only twice in view of the "dialogical engagement" of the translator's status which is more explained in view of "the dialogic principle" whereby the translator is

not alone but engaged [my emphasis] in obvious social dialogue with a number of partners: original writer, commissioner, publisher, potential readership, other members of the translating profession. Translators are equal partners in this dialogue, contributing their own particular expertise as links in the communicative chain. Furthermore, translators interact dialogically with themselves [...]. And they also engage in dialogue with the text itself, interacting intertextually with it, manipulating it, teasing another text out of it which then itself stands in a dialogic relation with the original [...]. The Dialogic Principle therefore concerns the communication norm: language is social, translating is a social act.

This following presents the relation between social interaction and the theory of the human mind, recalling G.H.Mead. It is the sense of self, which is fulfilled through an interaction with others, though the collective participation of the personal self with the social self. Pierce's definition of self as collection of signs seen as self through the individual himself, and seen by others in the society as 'person' because of the projection of these sign on, and the reflection and reaction by, them. Friday's Footprint by Brothers supports the ethno-methological approach as a logical basis of everyday thought.

Bloom asserts that a child first knows the word naming the object, and the target of that object next, and not vice versa. Steven Levinson and the special relation between objects is significant. It is based on the frame of reference whose choice is biased due to differing cultures. The inner speech could be resorted to by those native language is different from the language of speech because of being unfamiliar to that new language or rather to think in that new language of communication. He refers to the mentally handicapped as a reference to the relation between language and thought; the verbal inability is compensated by the ability to draw and means of gesture as a way to express their inner speech.

c. The word "literacy" with reference to the literacy story is basic to Olson's way of thinking. In a preface to Reconceptualizing Literacy in the New Age of multiculturalism and Pluralism, Henry T. Trueba (xvii) provides a curious definition of cultural pluralism:

Literacy in a broader Freirean sense brings a distinct commitment to social justice, commitment to defend human dignity and respect for cultural and linguistic varieties associated with different nations, cultures and life styles... . The ability to link historically our present (albeit oppressive it may be) to a brighter future in which a new social order may permit us to be who we are, is the roots and foundation of genuine democracy and cultural pluralism.

So, the matter is cultural and historical; The Educated Mind by the educator Kieran Egan (1997: 3) sees education as a significant tool to the welfare and survival of any society when the young of that society be aware of the their responsibility and how could they participate to uplift the surrounding culture of their society. He suggests that any strategy for educational reform should address the effects of education's long history, during which three educational goals have come into existence: "That we must shape the young to the current norms and conventions of adult society, that we must teach them the knowledge that will ensure their thinking conforms with what is real and true about the world, and that we must encourage the development of each student's individual potential."

The two views of Trueba and Egan indicated above are significant on the basis that Olson's attempt to decipher the textoral and written difficulties of a possible discourse is for the same purpose of literacy, especially the strategy of the literate mind. The eight principles he discusses are aspects of a theory that relates literacy and thought. Olson's emphasis on reading and writing as skills should be assimilated by everyone, reader or writer alike, in order to be aware of others' discourse. The link between literacy and thought is a scaffolding for the ability of a critical reader to exist. It seems that principle \#6 that lies in the indirectness of the written discourse, is mainly literary because the author determines his written discourse not enough to achieve a full understanding in order to make active the reader's skill of inference and power of reading between the lines with the use of his imagination-the reader's mind's eye. It is, in brief, 'how a reader took a statement" (523). It is in how all the interpretation of written texts calls for. This means that readers should accept the text as it is and try to communicate with its openness. All emphasis of theories of reading is concerned with what and not how it is conceived in a text.

\subsection{The Question of Dialogism}

The Russian philosopher and literary critic Bakhtin's philosophy of language is epitomized in the frequent discussion of scholars over the ages to include literary concepts and terminology such as "answerability" etc. In fact, over a period of five decades, from the 1920s to the 1970s, the "productive thinking" of Bakhtin has been noticed to extend for a period of thirty years in which he lived and worked in "relative obscurity" (Emerson 1984: xxix), and even he did not start to 
see his work widely published until the 1960s. This took him, and his commentators as a result, "through changes of topic, antagonist, method [---]. Nonetheless, certain indispensable ideas re-occur from era to era in his marches on the territory of the utterance, gaining new meanings from change of context: rather continuous embroidery than frequent abrupt instances of about-face" (ibid). An account of the utterance is the ambitious yet unfinished fate of Bakhtin, especially he felt the death of his word because his utterances were doomed to be unpublished, at the time in which he was persecuted and lived as an exile, in the Soviet Union.

a. The social act of verbal communication and of non-verbal written communication is true to Bakhtin's thought in a vital sense. In "Art and Answerability" (1990: 1), a polemic essay written in (1919), mainly before Bakhtin's Problems of Dostoevsky's Poetics, Bakhtin integrates the cultural unit and the linguistic unit in a responsible act of answerability:

A whole is called 'mechanical' when its constituent elements are united only in space and time by some external connection and are not imbued with the internal unity of meaning. The parts of such a whole are contiguous and touch each other, but in themselves they remain alien to each other.

The three domains of human culture - science, art, and life - gain unity only in the individual person who integrates them into his own way. [...] When a human being is in art, he is not in life, and conversely. There is no unity between them and no inner interpenetration within the unity of an individual person.

But what guarantees the inner connection of the constituent elements of a person? Only the unity of answerability. I have to answer with my own life for what I have experienced and understood in art.

In order to explain this passage, there is a need to review briefly the act of outer speech and inner speech. One of Bakhtin's contemporaries is Vygotsky, the psychologist, whose unity of "thinking and speech" or the inner speech, originated in his famous book Thought and Language (1934). He has been a leading topic to research in Soviet Psychology, which is in harmony with Bakhtin's thought, (Minick 1996). The way I see is that the outer speech refers to the cultural context, to everything around us, to the "external connection" and according to which there is an inner speech, which is relatively rooted within each of us as an answer to the cultural world; this inner speech is 'relative' because it depends on how much a person is involved in and sensitive to the cultural context. I prefer to phrase this encounter between inner speech and outer speech to confer a sort of struggle the result of which is the written use of language. The use of speech/language differs from one individual to another because of the power of the "inner connection" (dialogism). "Bakhtinian dialogism", according to Kristeva (1986:39), "identifies writing as both subjectivity and communication, or better, as intertextuality." Because Bakhtin is distinguished for the use of repetition in his assortments of writings, which means that he is able to provide varieties of the same thing in different contexts, therefore one maintains that he was able to embody the ultimate "unity of answerability". Bakhtin used the term "chronotope" to indicate the way time and space are used together represented in the particular sense that the individual should be answerable to life in art in the Bakhtinian philosophy of Becoming (cf. Anderson 1983). Accordingly, Bakhtin's view is to signify the carnival, "Indeed, a corollary of the 'Bakhtinising' of Carnival is the enslavement of literary analysis to social criticism" (Coronato 2003:14).

b. Let us have a look at how Bakhtin is still a problem to others. In their preface to the famous biography, Mikhail Bakhtin, where they explain the core of Bakhtinian thought (1984: ix), Clark and Holquist, two distinguished theorists and translators in the West, state that the problem of placing Bakhtin in general can be assigned to the existence of "a translation gap":

Bakhtin's early work expresses most clearly the task that occupied him throughout his life, that of turning his dialogism into a full-fledged world view, and yet the pertinent texts are only now being translated. These early works reveal the broad philosophical base on which rests his major regional thinking in linguistics, literary criticism, and social history. The difficulties due to the translation gap are compounded by the problem of authorship [---].This textological dilemma is a manifestation of the still greater dilemma of where to place Bakhtin, given the major gaps and conflicts in the available material.

Bakhtin's writings are problematic because of the relation of his thinking to everything in our life (Ibid: 6-7):

the demand that his way of thinking makes on our way of thinking, the demand to change the basic categories that most of us use to organize thought itself. [---] Bakhtin makes the enormous leap from dialectical, or partitive, thinking, which is still presumed to be the universal norm, to dialogic or relational thinking.

When the texts were published and translated in the West, Dentith (1995:3) distinguishes the characteristics of Bakhtin's utterance that issued into specific situations which lent them the force of other expectations and agendas. There is no betrayal here, no departure from a fixed original meaning, for the life of any word is a succession of utterances, in each of which its meanings are enriched, contested, or annexed. The words of Bakhtin himself are no exception. Yet there is an interesting corollary to this emphasis on the 'situatedness' of all utterances, which is that they must issue forth from one historically unique and particular place to another, indeed from one person to another, necessarily caught up in the complexities and inequities of social life.

Here, Dentith's view casts light on the translation of the word from the original that is doomed by nature not to be the same.The translator's inner and outer speech is different from that inner and outer speech of the author of the text planned to be translated into another language. Since the author is for Bakhtin "one of the strongest images of a morally aware construction of a self" (Wesling, 2003:20), the reality of the text is for the translator to translate into the other. In 
this sense, the individual inner and outer speech of Bakhtin allows Caryl Emerson to translate Bakhtin's Problems of Dostoevsky's Poetics (1984) into English.

Given that Bakhtin says very little on translation does not mean that his thought cannot be rethought in accordance with translation problems. It is important to bear in mind that many of the old and recent translation problems have already been reconsidered in one form or another in Bakhtin's dialogic stance. I will focus more on the relevance of Bakhtin's thought to translation from the following perspective of Clark and Holquist:

One of the difficulties posed by Bakhtin is to avoid thinking from within an all-pervasive simultaneity without at the same time falling into the habit of reducing everything to a series of binary oppositions not a dialectical either/or, but a dialogic both/and. At the heart of Bakhtin's work is a recognition of existence as a ceaseless activity, an enormous energy, which is constantly in the process of being produced by the very forces that it derives.

c. A question: what constitutes the full utterance [in what Bakhtin calls the "unit of speech communication" (1986:71)]?

An answer to this question underlies my research thesis of the question of answerability in this article. There are as many different answers to the question as there are different people. For example, Fonagy says that this "Visual and oral performance constitutes the full utterance" (Fonagy 2001: 363). Out of a very specific number of phonemes with a reduced number of their distinctive features, the result is a thousand of signs and an infinite number of utterances which Chomsky attributes, as cited in Fongay (Ibid: 619), to be "the most striking aspect of linguistic competence." 2 Furthermore, you reader may not have Fonagy's same response due to the fact that "The utterance corresponds to one or several situations" (Vinay and Darbelnet 1995: 12) in which you (I or we) are involved.

Based on the fact that in everyday life every language is "a polystystem" which leads to mass variations within a language (Arabic, English or any other language), this requires from us "a continuous act of translation. This is one essential element of dialogue"(Kloepfer 1981: 33). The extent to which a dialogue manages to be the task of the translator is determined objectively by the nature of Benjamin's sense of a "transformation and a renewal of something living - the original undergoes a change" (2000:17). Bhabha begins his essay, "How Newness Enters the World" with a quote from Benjamin: "Translation passes through continua of transformation, not abstract ideas of identity and similarity" (Bhabha 1994:212; Benjamin 2000:). The problem of the unfinalized utterance of Bakhtin is essential to the concept of equivalence/difference in translation. Equivalence, in contrast to difference, in view of the relevance of the role of the original text to the role of the translated text and the difference of the target from the original, could be the reason for translation researchers not to align Bakhtin's vision to translation views. More significant is to try to figure out how such dialogic difference appears to correspond in its aspects to be an extension of the far-reached meaning of equivalence between ST and TT (see Gorlee 2003). However, translation researchers have been in relentless search of the equivalence (not the difference) between the original and translation, nor have they tried to change the route of translation's focus on equivalence to the coinage of other terms with new associations of meaning!

For me, I consider the utterance of both equivalence and difference, two sound faces of one coin, to be the most important fact about translation, about "the totality of the message" (Vinay and Darbelnet 1995: 12) as the main concern of translators; and this particular view of the utterance will be, sooner or later, acknowledged. In doing so, the celebration of the paper gives "voice", in Bakhtin's sense, to a set of views with the worldview, which is a characteristic of 'Trans-Formations' par excellence. In plain terms, it is to keep in mind that the section of the metaphor of relation is to discuss the inseparable diversified relation of the cultural unit and the linguistic unit to be consistently bound to Bakhtin's "unit" in a dialogic act of communication.

\section{The Metaphor of Relation: The Big Picture}

In the view of Ong (1977: 10), the new studies involving the relation between the Occident (Europe and the Americas) and Central and West Africa "have been grouped around the dialectically related themes of change or alienation on the one hand and growth or integration on the other." A way of looking at the core of the function of language in the establishment of communication between speech communities is to think of translation, as Baker $(1992$, p. 4) aptly puts it, as a "discipline which has to concern itself with how meaning is generated within and between various groups of people in various cultural settings." The term "culture" then refers to the knowledge of the world that the members of a particular society share. It plays a crucial role in one's understanding of one's world and one must be familiar with it so that one can be familiar with others' behaviors and their attitudes, through "a set of semiotic systems, a set of systems of meaning, all of which interrelate" (Halliday, 1989: 4).

The translator as a talented reader (viewer) is able to avoid translation problems if he possesses a sound interpretation of "a number of choices, or procedures, guided by a reasoned perception of a number of contextual factors, which can finally be confirmed only by a reading of the whole text" (Newmark, 1991:126; see also Mukheriee 1994:139). The translation product has become thus a sign of the extent to which a translator understands what represents the insider's voice and the outsider's voice alike. It would be better if the task of the translator is to interpret the text reasonably rather than imposing one's personal understanding. The status of a translator as an outsider demands this highest level of reading in the pre-translation activity of interpretation which depends on the context where a situated word meaning is used in order to be able then, Mukheriee continues, to "restructure" the translator's interpretation in another language "while striving to approximate the original structure" (ibid).

\footnotetext{
${ }^{2}$ For further distinction between linguistic "competence" and linguistic "performance", see Chomsky and Saussure.
} 
This section presents an example of the relation of the utterance as the cultural unit of communication: the dilemma of those people, or "difficult" people who are difficult because they are hard to deal with. Brinkman and Kirschner (2006: 1) introduce this simple definition of such people: they are those people "you can't stand and who don't do what you want them to do or do what you don't want them to do--and you don't know what to do about them!". The following is a common ground to the ability of the reader to interpret an utterance. Look at the following two example as a postcolonial sign of answerability. The Palestinian-Jewish chaotic relationship results in the use of the language of power to connote meanings of the language of control. Words always encode rich meanings of powerful relations. The following two plates are given to demonstrate the sign interpretation of words; they derive from the sociolinguistic study made by Suleiman (2004) about the linguistic effect of the road signs in Jerusalem: the plate on the left side says "Falafel postcard" and the other plate on the right side is a sign of warning. The bold-faceted word is given in three languages: Hebrew, Arabic, and English. The Arabic word is given the bold-faceted shape which is equivalent to its corresponding English "DANGER" (see chapter 5 for further detail).

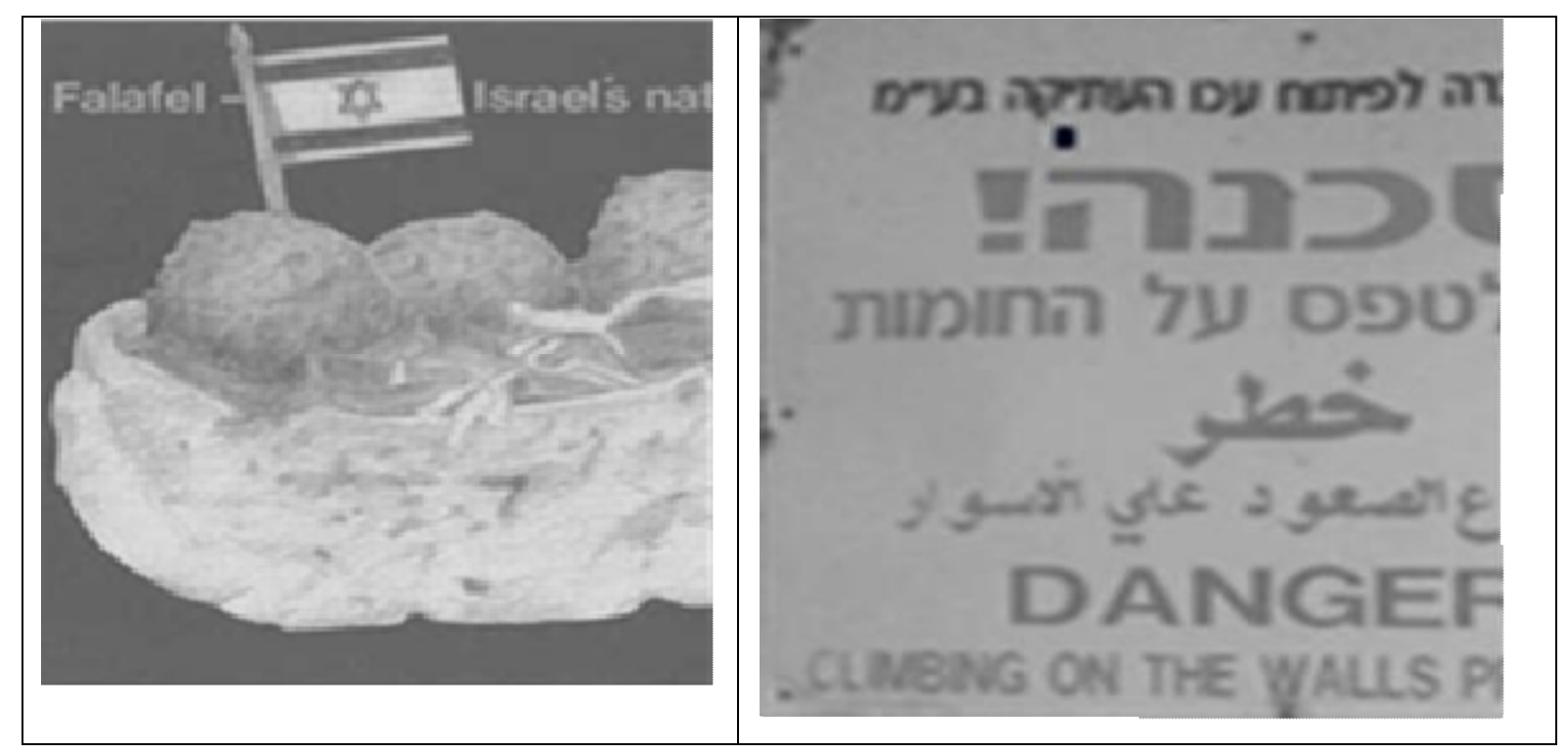

Fig. 1.2 The Two road-sign plates are given to demonstrate the sign interpretation of words

In this regard, in the introduction to this book, Suleiman (2004: 5) describes the particular focus of this ideologicalpolitical conflict:

The conflict between Arabic and Hebrew in Israel/Palestine combines the social and the political, although the latter is more dominant. Issues of national identity, state building, ethnic marking, map making and semiotic representation are involved in this conflict. The clash of irreconcilable ideologies in this conflict pervades the curriculum, the media and even the discourse of scientific investigation. The latter is a fascinating area. Studying the politics of sociolinguistics can help us understand that scholarly endeavour may not be as neutral or innocent as some members of the academy may sometimes think.

Indeed, research to date has not directly addressed the ideological complexity of the messages behind the road signs after Suleiman. The writer used the plate on the right side to be the jacket of his book (2004). Indeed, I have chosen these two plates from many of the plates given in Suleiman's book, as they reflect deeply the colonial language of control. The two Plates are important enough to reflect on the eventual Israeli-Palestinian situation, the self-other chaotic relation, that has been dominant long ago since 1948: a complete state of dominance and control over all the Palestinian lands and lives. First, the Plate on the left says: The pragmatic power of the Israeli flag on top of a famous Arabian food is a sign of the upper hand over everything, including lands, people, and the food "the popular food for all the majority of the Arab" as a sign of Arabic culture. The Plate on the right translates: the current debilitated position of the Palestinians under the Israeli regime. That is, the position of Arabic as a language of the emigrants to Israel makes the situation very difficult and people there got to believe that Arabic is the language of the weak when they observe how speakers of French, English, and Yiddish among Israeli Jewish people are dealt with respect. Further, top of the Arabic word is the Hebrew equivalent and the bottom of the same word is its English equivalent of "Danger". It signifies the meaning that the Arab are under the Hebrew and the English control. These two plates depict the unsecured and jeopardized life of the Arabic people of Palestine during their confrontation with the Israeli troops. The implicit message beyond the roads signs in Jerusalem is to reflect the present and future political agenda of Israel on the long run -- this is a call to arms!

In a word, an utterance is definitely acceptable to be a context-dependent meaning, viz. to be a contribution to interpretation via codes (linguistic signs) employed meaningfully (functionally) to the direct or indirect, explicit or implicit use of language. The setting of context is a reference to the situation of an utterance which is central to the 
verbal and non-verbal discourse. This means that discourse is a whole structure and its various constituents include the divergent and/or convergent employments of codes related to linguistics (semantics and pragmatics) and to nonlinguistics/ extralinguistics (sociolinguistics, psycholinguistics, and semiotics). The written discourse of he two plates discussed above indicates an argument, as it employs codes to convey (or to mean) the intention of what is said. This means that the meaning of what is said consequently categorizes into pragmatic discourse(s) in which an interpretation requires an endless set of interpretations.

\section{Conclusion}

Bakhtin's concept of dialogism is an aspect of a critical discourse in textual analysis. The dialogic difference in Bakhtin's sense was probably a reason for other researchers to see his notions too strange to apply to translation, and to ignore him accordingly. That is, the indirect self-realization of Bakhtin as a translationalist motivates me to refocus on his thought again in how it intersects with others through a web of confluences of answerability. In this particular sense, this article attempts to add to Bakhtin's two basic vocabularies of the intonation and speaking subject of dialogism, two concepts that seem to present briefly the dialogic principle of rhetoric: clash between inner speech and outer speech and the image of language. Each of such two terms discussed here presents the polyphony of voices as a discourse to be central to the intertextual study of translation. Given this stance of the confluences of cognition (a,b,c) and dialogism $(a, b, c)$, and how they all shade into one another, this bifurcated or hybridized article presents points of intersection on the synthetic nature of translation as a confluent activity towards the development of a distinct pedagogical method to translation as a crafty method-- a method that can be articulated between any two languages, Arabic and English), for example, or others Languages, in view of the relationships of difference between Source Text (ST) and Target Text (TT) in light of the analysis of their dialogical ways of thinking. Based on the fact that language, culture (memory), and thought are inextricably intertwined, and the analysis of one reflects the relevance of the others, I maintain that a study of the conflations between writing and translating, as it neatly posits an articulated tool to expand the effort in translation criticism between original and translation, as a tool by considering the dialogic nature of reception and distance, is a point of departure.

\section{References}

Baker, Mona. (1992). In Other Words: A Coursebook on Translation. London: Routledge.

Bakhtin, M. M. [1930s] (1981). The Dialogic Imagination: Four Essays. Michael Holquist (Ed.). Caryl Emerson and Michael Holquist (Trans.). Austin and London: University of Texas Press.

-----. (1990). Art and Answerability: Early philosophical Essays in Michael Holquist and Vadim Liapunov, (Eds.). Vadim Liapunov \& Kenneth Brostrom (Trans.). Austin: University of Texas Press.

----- (1986). The Problem of Speech Genres. Vern W.McGee (Trans.), Emerson \& Holquist (Eds.) In Speech Genres and Other Late Essays. Austin: University of Texas Press.

-----. (1986). "From Notes Made in 1970-71." Emerson and Holquist, 132-58.

----. (1984). Problems of Dostoevsky's Poetics. Caryl Emerson(Ed. \& Trans). Minneapolis: University of Minnesota Press.

Benjamin, Walter. (2000). "The task of the translator." H. Zohn (Trans.). In Lawrence Venuti \& Mona Baker (Eds.). The Translator Studies Reader. (Pp15-25). London: Routledge.

Bhabha, Homi K. (1994). The Location of Culture. London and New York: Routledge

Brinkman, R. \& Kirschner, R. (2006). Dealing with Difficult People. New York: McGraw-Hill.

Chesterman, Andrew. (1997). Memes of Translation: The Spread of Ideas in Translation Theory. Amsterdam: John Benjamins.

Coronato, R. (2003). Jonson Versus Bakhtin: Carnival and the Grotesque (Textxet 41) (Textxet Studies in Comparative Literature). Amsterdam: Rodopi.

Dentith, S. (1995). Bakhtinian Thought: An Introductory Reader. Routledge.

Egan, K. (1997). The Educated Mind: How Cognitive Tools Shape our Understanding. Chicago: The U Chicago Press.

Fonagy, I. (2001). Languages Within Language: An Evolutive Approach. Amsterdam: John Benjamins.

Giddens, Anthony. (1990). The Consequences of Modernity. Stanford University Press.

Halliday, M.A.K. \& Hasan, Ruqaiya. (1989/ 1985). Language, Context, and Text: Aspects of Language in a SocialSemiotic Perspective. ( $2^{\text {nd }}$ ed. ). Oxford: Oxford UP.

Holquist M. (1981). The Dialogic Imagination: Four Essays / by M. M. Bakhtin. Edited by Michael Holquist; Caryl Emerson and Michael Holquist, trans. Austin : University of Texas Press.

Kloepfer, R. (1981). Intra-and intercultural translation. Poetics Today. Vol.2 (4). 29-37.

Lenneberg, E. (1967). Biological Foundations of Language. New York: John Wiley and Sons. 
Minick, N. (1996). The Development of Vygotsky's Thought. In Introduction to Vygotsky (pp. 28-52). New York: Routledge.

Mukherjee, S. (1994). Translation as Discovery. (2 ${ }^{\text {nd }}$ ed.) Hyderabad: Orient Longman.

Osgood, C., et al. (1957). The Measurement of Meaning. Urbana, IL: U of Illinois P.,

Ong, W.J (1977). Interfaces of the Word" Studies in the Evolution of Consciousness and Culture. Ithaca: Cornell University Press.

Plotkin, H. (1993). Darwin Machines and The Nature of Knowledge. London: Penguin Books.

Richard E., P. \& Samovar, L. A. (1976). Communicating Interculturally. In Intercultural Communication: A Reader. ( $2^{\text {nd }}$ ed.). Larry A.Samovar and Richard E., (Eds.). Porter. Belmont, California: Wadsworth: 4-24.

Sperber, D. \& Wilson, D. (1986). Relevance: Communication and Cognition. Cambridge MA: Blackwell: Oxford University Press. (Second edition 1995. Blackwell, Oxford).

Suleiman, Yasir. (2004). A War of Words: Language and Conflict in the Middle East. Cambridge: Cambridge UP. (Chapter 5).

Sechrest, L., Fay, T.L. \& Hafeez Zaidi, S.M. (1988/1972). Problems of Translation in Cross- Cultural Research” In L.A. Samovar \& R.E. (1995). Porter (Eds.) Intercultural Communication: A Reader (5th edition). Belmont: Wadsworth. The Longman Dictionary of Contemporary English.

Tomasello, M. (1999). The Cultural Origins of Human Cognition. Harvard: Harvard UP.

Trueba, H. (2001). Preface. In Patricia Ruggiano Schmidt and Peter B. Mosenthal (Eds.). Reconceptualizing Literacy in the New Age of Multiculturalism and Pluralism. Greenwich, Conn.: Information Age Pub.

Tyler, S. (1969). Cognitive Anthropology: Readings. New York : Holt, Rinehart and Winston.

Vinay, J. P. and Jean. P. (1958/1995). Comparative Stylistics of French and English: A Methodology for Translation. Juan C. Sager \& M.-J. Hamel, (Trans. \& eds.) Amsterdam: John Benjamins

Werner, O. \& Campbell, D. (1970). Translating, Working through Interpreters and the Problem of Decentering. In R. Naroll \& R. C. (Eds.). Handbook of Cultural Anthropology. New York: American Museum of National History. 